\title{
Hot Consolidation of Partially Amorphous Cu-Ti Based Alloy: a Comparison Between Hot Extrusion and Hot Compaction by Sintering
}

\author{
Bruno Bellini Medeiros ${ }^{a *}$, Cláudio Shyinti Kiminani ${ }^{b}$, Walter José Botta ${ }^{b}$, \\ Claudemiro Bolfarini ${ }^{b}$, Alberto Moreira Jorge Junior ${ }^{b}$ \\ aPrograma de Pós-Graduação em Ciência e Engenharia de Materiais - PPG-CEM, \\ Universidade Federal de São Carlos - UFSCar, Rodovia Washington Luís, \\ km 235 - SP-310, CEP 13565-905, São Carlos, SP, Brazil \\ ${ }^{b}$ Departamento de Engenharia de Materiais - DEMa, Universidade Federal de São Carlos - UFSCar, \\ Rodovia Washington Luis, km 235 - SP-310, CEP 13565-905, São Carlos, SP, Brazil
}

Received: March 10, 2014; Revised: April 8, 2015

\begin{abstract}
Consolidation of amorphous powders, which take advantage of the supercooled liquid region, is an alternative way to overcome the size limitation in marginal metallic glasses. $\mathrm{Cu}_{36} \mathrm{Ti}_{34} \mathrm{Zr}_{22} \mathrm{Ni}_{8}$ based amorphous powders were obtained during high energy ball-milling. The analyses revealed that amorphous structures of powders and ribbons are quite different and this led to a different thermal behavior being the powders more thermally stable than the ribbons. Extrusion was initially proposed as a consolidation process; however, the decrease in viscosity in remainder amorphous matrix was not sufficient for that process, but certainly sufficient for sintering the sample during hot consolidation. An amorphous/nanocrystalline microstructure known for enhancing the mechanical properties of their fully amorphous counterparts was obtained. Evaluation of mechanical properties by microhardness revealed the relatively high hardness of HV 768 . From these results, consolidation by sintering seems a promising route to produce bulk metallic glasses nanocomposites.
\end{abstract}

Keywords: nanocomposites, consolidation, amorphous alloys

\section{Introduction}

$\mathrm{Cu}$-Ti based bulk metallic glasses (BMG) alloys have attracted interest due to their superior mechanical properties and relatively lower costs ${ }^{1-4}$. However, the lack of ductility has limited the applications. To overcome this problem, composites of embedded nanocrystals in the $\mathrm{Cu}$-Ti glassy matrix are being developed. ${ }^{5,6}$. Furthermore, normal casting routes present the issue of size limitation, in which the largest obtained thickness was around $5 \mathrm{~mm}^{3}$. The route of solid state amorphization followed by powder consolidation appears to be an attractive route to produce sized BMGs in alloy systems with marginal glass forming ability, as is the case of $\mathrm{Cu}$-Ti-based alloys. Processes of amorphization by mechanical alloying have been described in Cu-Ti-Zr-Ni systems ${ }^{7-9}$. Consolidation of amorphous powder can be achieved by ultra-high pressure (UHP), by taking advantage of the decrease in viscosity of the supercooled-liquid region ${ }^{10}$, sintering-spark plasma (SPS) $)^{11-13}$, equal channel angular extrusion (ECAE) $)^{14}$ and extrusion ${ }^{15}$. According to preliminary tests $^{16}$, the $\mathrm{Cu}_{36} \mathrm{Ti}_{34} \mathrm{Zr}_{22} \mathrm{Ni}_{8}$ alloy is a strong candidate to form metallic glass. It has been shown ${ }^{16}$ that this alloy presents amorphous phase formation when processed by melt spinning showing supercooled-liquid region $\left(\Delta \mathrm{T}_{\mathrm{x}}=\mathrm{T}_{\mathrm{x}}-\mathrm{T}_{\mathrm{g}}\right)$, $\Delta \mathrm{T}_{\mathrm{X}}=67 \mathrm{~K}^{16}$. The Assuming that $\mathrm{Cu}$ and $\mathrm{Ni}$ are similar, $\mathrm{Cu}_{36} \mathrm{Ti}_{34} \mathrm{Zr}_{22} \mathrm{Ni}_{8}$ composition is located near to deep eutectic in a $\mathrm{Cu}-\mathrm{Ti}-\mathrm{Zr}$ ternary phase diagram, which decreases the

*e-mail: brunojau@gmail.com probability of intermetallic phases precipitation ${ }^{17}$. Therefore, in the present paper, the $\mathrm{Cu}_{36} \mathrm{Ti}_{34} \mathrm{Zr}_{22} \mathrm{Ni}_{8}$ alloy was chosen to produce an amorphous structure by ball milling followed by hot compaction and sintering.

\section{Experimental}

$\mathrm{Cu}_{36} \mathrm{Ti}_{34} \mathrm{Zr}_{22} \mathrm{Ni}_{8}$ alloy ingots were prepared by arc-melting of high purity constituent elements (i.e., $\mathrm{Cu}(99,99 \%)$, $\mathrm{Ti}(99,99 \%)$, and $\mathrm{Zr}(99,50 \%), \mathrm{Ni}(99,99 \%))$ in a high-purity argon gas atmosphere and using Ti-gettering. All the ingots were re-melted at least 4 times to obtain a homogeneous master alloy. The ingots were crushed in a hammer-forging die before milling. After crushing, the material was loaded together with hardened-steel balls in a hardened steel vial to perform milling with a ball-to-powder ratio of 30:1. The ball milling process was performed in a Zoz Simoloyer with water cooling temperature control, at $900 \mathrm{rpm}$, under purified argon gas atmosphere during 8 and 16 hours. The obtained powders were cold compacted at room temperature under $1 \mathrm{GPa}$ of uniaxial pressure. Finally, samples with a diameter of $4.5 \mathrm{~mm}$ were produced by hot-extrusion, which was done inside the supercooled liquid region at $736 \mathrm{~K}$, with ram speed of $1 \mathrm{~mm} / \mathrm{min}$ and an extrusion ratio of 3:1. The structural characterizations of powder and extruded samples were performed by X-ray diffraction (DRX) in a Siemens D5005 diffractometer with $\mathrm{CuK} \alpha$ radiation, and transmission 
electron microscopy (TEM) in a Tecnai F20 Philips. The glass transition $\left(\mathrm{T}_{\mathrm{g}}\right)$ and crystallization $\left(\mathrm{T}_{\mathrm{x}}\right)$ temperatures were determined by differential scanning calorimetry in a Netzsch DSC 200F3 Maia at a rate of $0.67 \mathrm{~K} / \mathrm{s}$. The mechanical properties were analyzed by using a Omnimet MHT Buehler - Wilson Hardness Tukon 1102 system with Vickers indenter loaded by $500 \mathrm{~g}$. The system is automatic and applies the load during a time following ASTM E384 ${ }^{18}$, and ISO $6507-1^{19}$ standards.

\section{Results and Discussion}

Figure 1 shows the comparison between the XRD patterns of ribbon ${ }^{16}, 8 \mathrm{~h}$ and $16 \mathrm{~h}$ ball-milled powders, and crystalline powders. This comparison shows that ball-milled powders did not present well-defined crystalline peaks, and that both peak-broadening and peak-positions are not matched to the ones for the ribbon. This can be an indication that the mechanism of amorphization is not the same. It has been reported that during ball-milling of pre-alloyed powders, the amorphization is thought to occur by the accumulation of structural defects such as vacancies, dislocations, grain boundaries, and anti-phase boundaries ${ }^{20}$. In comparison with amorphous alloys obtained by rapid solidification, the amorphization through reactions in the solid state has, in principle, the advantage to lead to techniques for producing bulky amorphous materials ${ }^{21}$. Moreover, due to the processing characteristics, it is reasonable to imagine that the physical properties, such as Tg and Tx of an amorphous alloy produced by the solid state reaction during milling, may be different from those of the amorphous alloy prepared by rapid cooling ${ }^{21}$.

In accordance with what was expected from the phase diagram, the unique phase precipitated in crystalline powder is $\mathrm{Cu}_{2} \mathrm{TiZr}$ and the solid solution of $\mathrm{Cu}$ with $\mathrm{Ni}$ shifted the peaks slightly to right. If one compares the ball-milled powder with the crystalline ones, the small peaks appearing at about 30, 35 and 63 degrees (the more intense) can be assigned as being the zirconium oxide, produced during milling. Due to the presence of higher intense peaks in the crystalline powders, $\mathrm{ZrO}$ does not appear in the spectrum and this is an indication that $\mathrm{ZrO}$ comprises less than $5 \%$ of the whole matrix.

Figure 2 presents the DSC curves of ball-milled powder in comparison with the ribbon, before correction of internal relaxation. The DSC curves confirm the formation of a totally different amorphous phase in the powders, which presented a higher glass transition temperature $\left(\mathrm{T}_{\mathrm{g}}\right)$ and onset of the primary crystallization $\left(\mathrm{T}_{\mathrm{x}}\right)$ than the ribbons. Moreover the $\mathrm{T}_{\mathrm{g}}$ and $\mathrm{T}_{\mathrm{x}}$ for ribbons are respectively about $100 \mathrm{~K}$ and $72 \mathrm{~K}$ lower than the ones for ball-milled powders. This will reflect in a larger supercooled liquid region for ribbons, $\Delta \mathrm{T}_{\mathrm{x}}=67 \mathrm{~K}$, when compared with the ball-milled powders, i.e., $\Delta \mathrm{T}_{\mathrm{x}}=39 \mathrm{~K}$ and $\Delta \mathrm{T}_{\mathrm{x}}=36 \mathrm{~K}$, respectively for 16 and 8 hours. Even with lower $\Delta \mathrm{Tx}$, the highest Tx observed for the powders means highest thermal stability ${ }^{22}$, which may be good for final mechanical applications. However, this will also create difficulties for further powder hot-consolidation due to the reduction of the window processing.

Figure 3 shows the bright field TEM images (BF-TEM) and selected area electron diffraction patterns (SAEDP) for both $8 \mathrm{~h}$ and $16 \mathrm{~h}$ ball-milled powders. From these images, it is not possible to observe the presence of nanocrystals, because they are BF images whose contrast can be influenced by differences in thickness. However, the SAEDP of powders milled till $8 \mathrm{~h}$ is showing the presence of an almost continuous ring formed by small white spots inside a diffused halo, indicating the presence of very small crystals inside of an

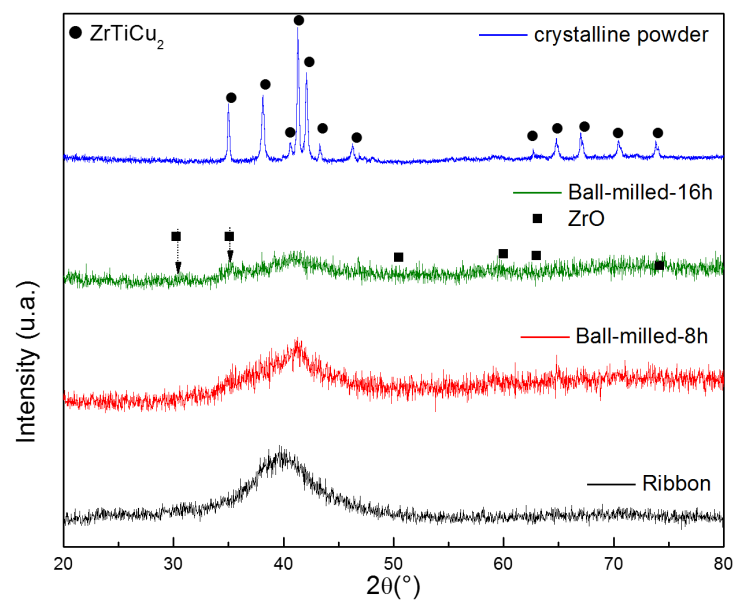

Figure 1. X-ray diffraction patterns of melt-spun ribbon, ball-milled powders ( $8 \mathrm{~h}$ and $16 \mathrm{~h}$ ) and crystalline powders of $\mathrm{Cu}_{36} \mathrm{Ti}_{34} \mathrm{Zr}_{22} \mathrm{Ni}$ alloy.

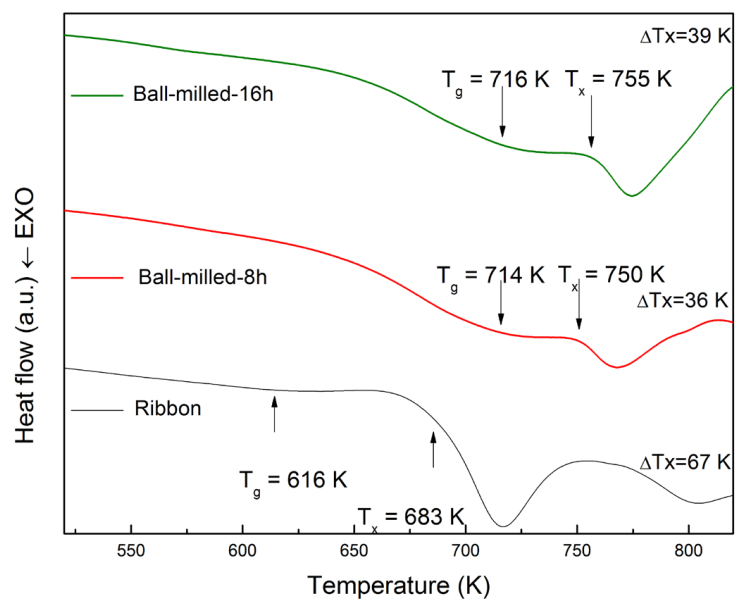

Figure 2. DSC curves for melt-spun ribbon and for ball-milled powders ( $8 \mathrm{~h}$ and $16 \mathrm{~h}$ ) of $\mathrm{Cu}_{36} \mathrm{Ti}_{34} \mathrm{Zr}_{22} \mathrm{Ni}_{8}$ alloy.
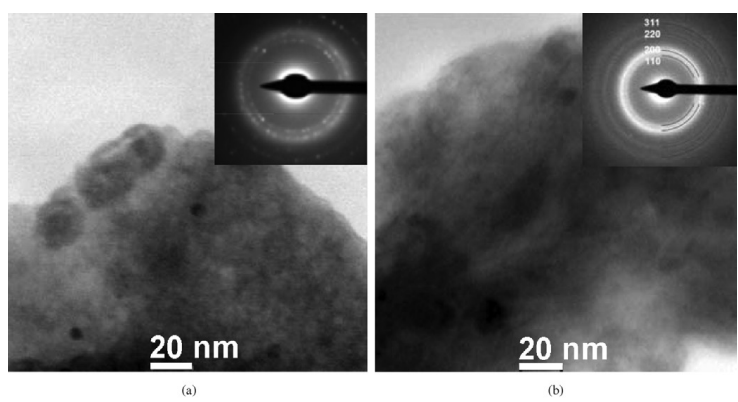

Figure 3. Bright field image and SAEDP of $\mathrm{Cu}_{36} \mathrm{Ti}_{34} \mathrm{Ni}_{8} \mathrm{Zr}_{22}$ ballmilled powders. (a) $8 \mathrm{~h}$ and (b) $16 \mathrm{~h}$. 
amorphous structure. The SAEDPs for powders milled for $16 \mathrm{~h}$ is showing a broader diffraction halo, when compared with $8 \mathrm{~h}$ of milling, as well as continuous outer rings formed by very small spots. The indexation of these outer halos indicated the presence of $\mathrm{ZrO}$, which increased with the milling time. The increased broadening and the absence of in-halo spots indicate that the sample is totally or, at least for the BF condition, "electron-diffraction" amorphous.

These nanocrystals can be better observed in Figure 4 which presents images of high resolution transmission electron microscopy (HRTEM) of the same regions presented in Figure 3. Figure 4a clearly shows cross-grating of Moiré lattice fringes, which are highlighted by red dashed circles and zoomed in the lower right inset, also confirmed by the Fast Fourier Transform (FFT) in the upper right inset, which presents a very high amount of spots. Even considering that they were barely observed, these lattice fringes indicate the precipitation of nanocrystals within the amorphous matrix ${ }^{23}$. The sizes of these nanocrystals were estimated to be about $20 \mathrm{~nm}$. Figure $4 \mathrm{~b}$ does not show clear evidence of nanocrystallization and the FFT presented in the inset clearly shows a pure amorphous state, which indicates that
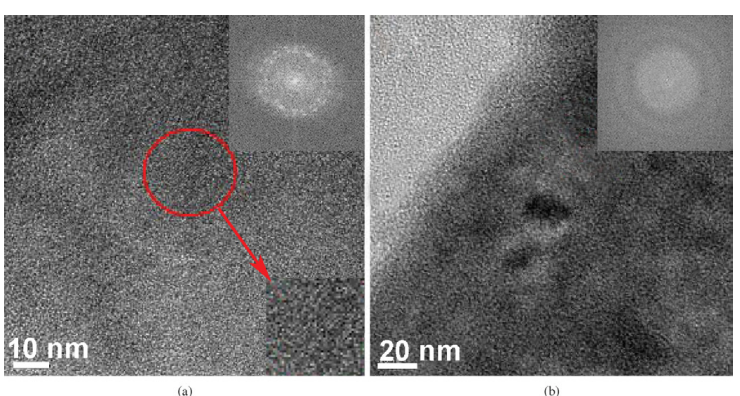

Figure 4. HRTEM images of $\mathrm{Cu}_{36} \mathrm{Ti}_{34} \mathrm{Ni}_{8} \mathrm{Zr}_{22}$ ball-milled powders (a) $8 \mathrm{~h}$ and (b) $16 \mathrm{~h}$. the effect of additional milling time resulted in a greater amorphous amount.

Moreover, the reinforced composite BMG/nanocrystals have been proven effective in improving their mechanical properties $^{5}$. Even the extrusion process has been done in the supercooled liquid region, just a small part of the sample could be fully extruded (Figure 5a). This can be explained by effective nanocrystallization during the passage in the conical region (partially extruded), where the material is subjected to an intense shearing and locally generates heat ${ }^{24,25}$. This can induce localized nanocrystallization which increases the viscosity. In this context, the pressure needed to continue the process became too high for the pressure machine and it was impossible to continue the process. Further, the extruded part presented brittle behavior, and it was not possible to cut the sample for further preparation. Nevertheless, the previous part of the sample was intensely hot compacted by simple sinterization (Figure 5b) and the amorphous matrix was preserved. This can be observed in Figure 6a where the XRD pattern shows that the amorphous matrix is maintained inside the hot consolidated sample, but there was also a noticeable nanocrystallization indicated by an evolution of the intensity of crystalline peaks. The maintenance of amorphous matrix is also confirmed by the DSC curve presented in Figure 6b which shows crystallization and an increase of both $\mathrm{T}_{\mathrm{g}}$ and $\mathrm{T}_{\mathrm{x}}$ temperatures, resulting in a $\Delta T_{x}$ of $40 \mathrm{~K}$.

Figure 7 shows images of BF-TEM, SAEDP in the inset of Figure 7a, and HRTEM of 16h ball-milled hot consolidated sample (Figure 7b). As was the case in Figure 3, from Figure $7 \mathrm{a}$ it is not possible to observe the presence of nanocrystals, but, differently from SAEDPs of Figure 3, the SAEDP of Figure 7 shows the presence of a continuous ring formed by small white spots inside a diffused halo. This means that crystals with very small sizes are embedded in the amorphous matrix and that these sizes are even smaller than the ones in Figure 3. These

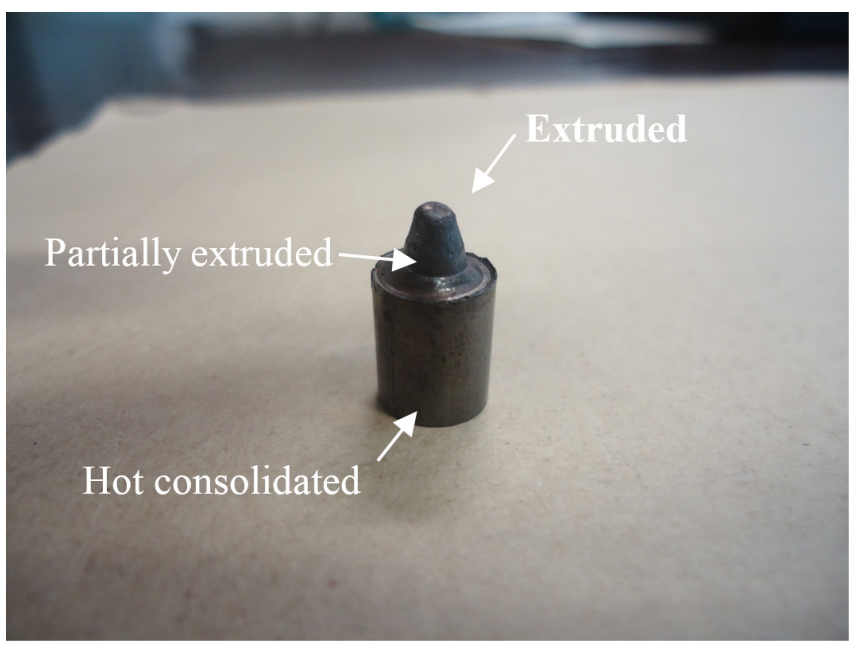

(a)

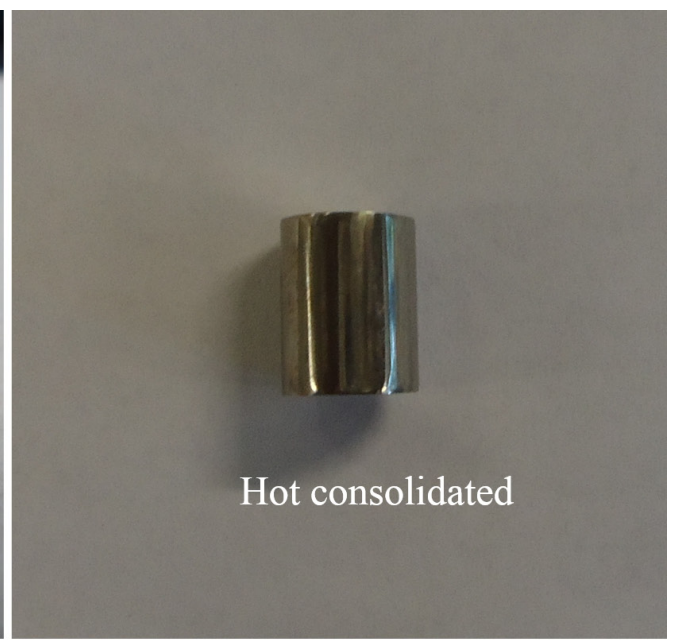

(b)

Figure 5. (a) Hot extruded sample; (b) hot consolidated of $16 \mathrm{~h}$ ball-milled $\mathrm{Cu}_{36} \mathrm{Ti}_{34} \mathrm{Zr}_{22} \mathrm{Ni}$ powders. 


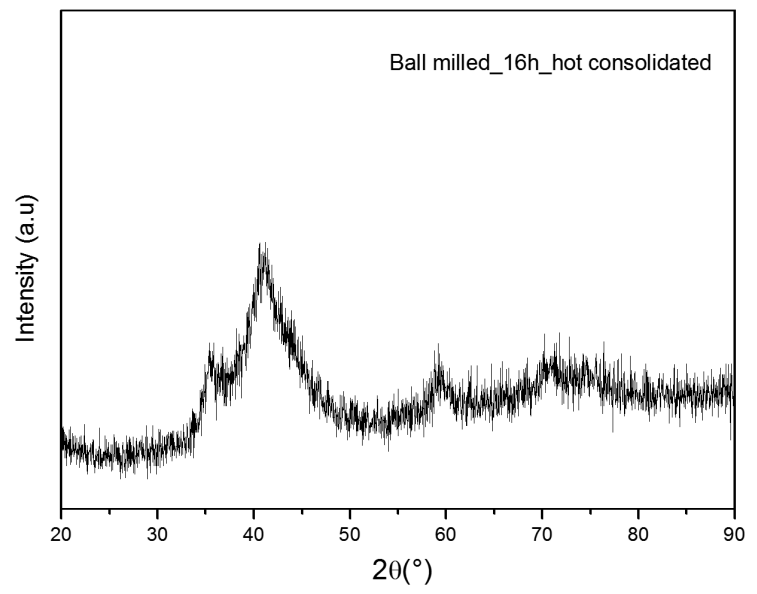

(a)

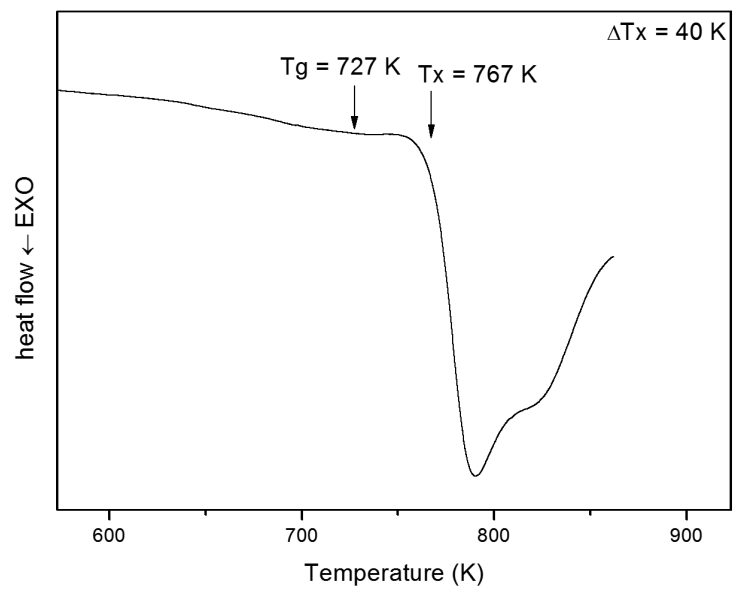

(b)

Figure 6. (a) X-ray diffraction pattern and; (b) DSC curve for $16 \mathrm{~h}$ ball-milled hot consolidated of $\mathrm{Cu}_{36} \mathrm{Ti}_{34} \mathrm{Zr}_{22} \mathrm{Ni}$ alloy.
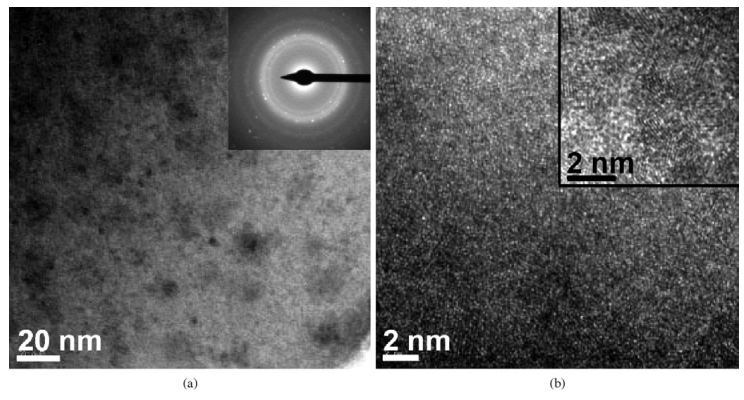

Figure 7. (a) Bright field image and SAED pattern; (b) HRTEM image of $16 \mathrm{~h}$ ball-milled hot consolidated $\mathrm{Cu}_{36} \mathrm{Ti}_{34} \mathrm{Ni}_{8} \mathrm{Zr}_{22}$ powders.

nanocrystals can be better observed in Figure $7 \mathrm{~b}$ which presents HRTEM images of the same region presented in Figure 7a. Figure 7b clearly shows cross-grating of Moiré lattice fringes in the upper-right inset of the Figure, and this is clear evidence of precipitation of nanocrystals within the amorphous matrix. The sizes of these nanocrystals were estimated to be about $2 \mathrm{~nm}$.

The hardness test results show that the hot consolidated sample reaches HV 768. If one can assume that the yield strength $(\rho)$ is $\rho \approx H V / 3,6^{14,26}$ this will give $\rho \approx 2765 \mathrm{MPa}$. These values can be considered relatively high when compared with others billets obtained in a consolidation process of $\mathrm{Cu}$-Ti based alloys ${ }^{13}$.

From these results, it is apparent that traditional powder metallurgy followed by sinterization can be successfully

\section{References}

1. Li P, Wang G, Ding D and Shen J. Glass forming ability, thermodynamics and mechanical properties of novel $\mathrm{Ti}-\mathrm{Cu}-$ Ni-Zr-Hf bulk metallic glasses. Materials \& Design. 2014; 53:145-151. http://dx.doi.org/10.1016/j.matdes.2013.06.060.

2. An J, Yim H and Haein C-Y. Compositional dependence of thermal and elastic properties of $\mathrm{Cu}-\mathrm{Ti}-\mathrm{Zr}-\mathrm{Ni}$ bulk metallic used to produce sized BMGs or, at least, composites of BMG matrix and nanocrystals which can produce materials with enhanced mechanical properties.

\section{Summary and Conclusions}

Amorphous/crystalline nanocomposite powders were produced by high energy ball-milling and consolidated during hot extrusion process. Microstructural, thermal and mechanical investigations were carried out.

The microstructural and thermal analysis revealed the different mechanism of amorphization of the powders when compared with ribbons. Powders milled for $16 \mathrm{~h}$ presented highest thermal stability indicated by highest crystallization temperature.

The amorphous matrix with embedded nanocrystals microstructure was maintained during extrusion. The hot consolidated samples presented a hardness value of 768 $\mathrm{HV}$ which is relatively higher than for other $\mathrm{Cu}$-Ti based billets produced by similar consolidation process.

Traditional powder metallurgy followed by sinterization is a promising route to produce sized BMGs with enhanced mechanical properties.

\section{Acknowledgements}

The authors thank the National Council for Scientific and Technological Development (CNPq - Brazil) for a doctoral grant and Foundation for Research Support of the State of São Paulo (FAPESP - Brazil) - Thematic Project for financial support.

glasses. International Journal of Minerals, Metallurgy, and Materials. 2010; 17(3):318-322. http://dx.doi.org/10.1007/ s12613-010-0311-y.

3. Yang YJ, Kang FW, Xing DW, Sun JF, Shen QK and Shen J. Formation and mechanical properties of bulk $\mathrm{Cu}-\mathrm{Ti}-\mathrm{Zr}-\mathrm{Ni}$ metallic glasses with high glass forming ability. Transactions of Nonferrous Metals Society of China. 2007; 17(1):16-20. http://dx.doi.org/10.1016/S1003-6326(07)60041-7. 
4. Inoue A, Amiya K, Katsuya A and Masumoto T. Mechanical properties and thermal stability of Ti- and Al-based amorphous wires prepared by a melt extraction method. Materials Transactions, JIM. 1995; 36(7):858-865. http://dx.doi.org/10.2320/ matertrans 1989.36.858.

5. Calin M, Eckert J and Schultz L. Improved mechanical behavior of $\mathrm{Cu}$-Ti-based bulk metallic glass by in situ formation of nanoscale precipitates. Scripta Materialia. 2003; 48(6):653658. http://dx.doi.org/10.1016/S1359-6462(02)00560-2.

6. Gargarella P, Pauly S, Samadi Khoshkhoo M, Kühn U and Eckert J. Phase formation and mechanical properties of $\mathrm{Ti}-\mathrm{Cu}-\mathrm{Ni}-\mathrm{Zr}$ bulk metallic glass composites. Acta Materialia. 2014; 65:259269. http://dx.doi.org/10.1016/j.actamat.2013.10.068.

7. Dutkiewicz J, Litynska-Dobrzynska L, Rogal L, Maziarz W and Czeppe T. Cu/Ti base multicomponent amorphous Cu47Ti33Zr11Ni8Si1 and nanocrystalline silver composites. Physica Status Solidi a-Applications and Materials Science. 2010; 207(5):1109-1113. http://dx.doi.org/10.1002/pssa.200983352.

8. Liu XD, Nagumo M and Umemoto M. Characterizations of mechanically alloyed $\mathrm{Ti}-\mathrm{Zr}-\mathrm{Cu}-\mathrm{Ni}$ powders. Materials Science and Engineering A. 1998; 252(2):179-187. http:// dx.doi.org/10.1016/S0921-5093(98)00693-5.

9. Dutkiewicz J, Lityńska-Dobrzyńska L, Kovacova A, Molnarova M, Rogal L and Maziarz W. HRTEM studies of amorphous ZrNiTiCu nanocrystalline composites. Journal of Microscopy. 2010; 237(3):237-241. http://dx.doi.org/10.1111/j.13652818.2009.03230.x. PMid:20500372

10. Dutkiewicz J, Jaworska L, Maziarz W, Czeppe T, Lejkowska M, Kubíček M, et al. Consolidation of amorphous ball-milled $\mathrm{Zr}-\mathrm{Cu}-\mathrm{Al}$ and $\mathrm{Zr}-\mathrm{Ni}-\mathrm{Ti}-\mathrm{Cu}$ powders. Journal of Alloys and Compounds. 2007; 434-435:333-335. http://dx.doi.org/10.1016/j. jallcom.2006.08.201.

11. Choi PP, Kim JS, Nguyen OTH and Kwon YS. Ti50Cu25Ni20Sn5 bulk metallic glass fabricated by powder consolidation. Materials Letters. 2007; 61(23-24):4591-4594. http://dx.doi.org/10.1016/j. matlet.2007.02.066.

12. Kim T-S, Lee J-K, Kim H-J and Bae J-C. Consolidation of Cu54Ni6Zr22Ti18 bulk amorphous alloy powders. Materials Science and Engineering A. 2005; 402(1-2):228-233. http:// dx.doi.org/10.1016/j.msea.2005.04.044.

13. Kim CK, Lee HS, Shin SY, Lee JC, Kim DH and Lee S. Microstructure and mechanical properties of $\mathrm{Cu}$-based bulk amorphous alloy billets fabricated by spark plasma sintering. Materials Science and Engineering A. 2005; 406(1-2):293-299. http://dx.doi.org/10.1016/j.msea.2005.06.043.

14. Zhang LC, Xu J and Ma E. Consolidation and properties of ball-milled Ti50Cu18Ni22A14Sn6 glassy alloy by equal channel angular extrusion. Materials Science and Engineering A. 2006; 434(1-2):280-288. http://dx.doi.org/10.1016/j.msea.2006.06.085.

15. Sordelet DJ, Rozhkova E, Besser MF and Kramer MJ. Consolidation of gas atomized Cu47Ti34Zr11Ni8 amorphous powders. Journal of Non-Crystalline Solids. 2003; 317(1-2):137143. http://dx.doi.org/10.1016/S0022-3093(02)01994-4.

16. Medeiros BB, Medeiros MM, Botta WJ, Kiminami CS, Oliveira MF and Bolfarini C. Estudo da capacidade de formação de estrutura amorfa das ligas Ti34Cu36Ni8Zr22 E (TiZr)80Co12Fe8. In: Proceedings of the $64^{\circ}$ Congresso Anual da Associação Brasileira de Metalurgia e Materiais; 2009; Belo Horizonte, Brazil. São Paulo: Associação Brasileira de Metalurgia e Materiais; 2009. CD-ROM.

17. Woychik CG and Massalski TB. Phase-diagram relationships in the system Cu-Ti-Zr. Zeitschrift fur Metallkunde. 1988; 79:149-153.

18. American Society for Testing and Materials - ASTM. Standard E384. Standard test method for knoop and vickers hardness of materials. West Conshohocken; 2003.

19. International Organization for Standardization - ISO. ISO 6507-1. Metallic materials-vickers hardness test-part 1, test method. ISO; 2005.

20. Suryanarayana C. Mechanical alloying and milling. Progress in Materials Science. 2001; 46(1-2):1-184. http://dx.doi. org/10.1016/S0079-6425(99)00010-9.

21. Schultz L. Preparation of thick amorphous metals by jelly roll technique and rapid diffusion. In: Von Allmen M, editor. Amorphous metals and non-equilibrium processing, MRS 1984 conference proceedings; 1984; Les Ulis, France. Les Ulis: Les Editions de Physique; 1984. p. 135-140.

22. Suryanarayana $\mathrm{C}$ and Inoue A. Bulk metallic glasses. Boca Raton: CRC Press; 2011.

23. Williams DB and Carter CB. Transmission electron microscopy: a textbook for materials science. New York: Springer; 2009.

24. Kawamura Y, Inoue A, Sasamori K and Masumoto T. Consolidation mechanism of aluminum-based amorphous alloy powders during warm extrusion. Materials Science and Engineering A. 1994; 181-182:1174-1178. http://dx.doi.org/10.1016/09215093(94)90826-5.

25. Kawamura Y, Kato H, Inoue A and Masumoto T. Full strength compacts by extrusion of glassy metal powder at the supercooled liquid state. Applied Physics Letters. 1995; 67(14):2008-2010. http://dx.doi.org/10.1063/1.114769.

26. Chen HS, Krause JT and Coleman E. Elastic constants, hardness and their implications to flow properties of metallic glasses. Journal of Non-Crystalline Solids. 1975; 18(2):157-171. http:// dx.doi.org/10.1016/0022-3093(75)90018-6. 